\title{
Bioaugmentation of a rotating biological contactor for degradation of 2-fluorophenol
}

\author{
Anouk F. Duque, Vânia S. Bessa, Maria F. Carvalho, Paula M.L. Castro* \\ CBQF/Escola Superior de Biotecnologia, Universidade Católica Portuguesa, Rua Dr. António Bernardino de Almeida, 4200-072 Porto, Portugal
}

\begin{abstract}
A B S T R A C T
The performance of a laboratory scale rotating biological contactor $(\mathrm{RBC})$ towards shock loadings of 2 fluorophenol (2-FP) was investigated. During a period of ca. 2 months organic shock loadings of $25 \mathrm{mg} \mathrm{L}^{-1}$ of 2-FP were applied to the RBC. As no biodegradation of 2-FP was observed, bioaugmentation of the RBC with a 2-FP degrading strain was carried out and, along ca. 6 months, organic shock loadings within a range of $25-200 \mathrm{mg} \mathrm{L}^{-1}$ of 2-FP were applied. Complete biodegradation of $50 \mathrm{mg} \mathrm{L}^{-1}$ of 2 -FP was observed during operation of the reactor. The RBC showed to be robust towards starvation periods, as after ca. 1 month of non-supply of the target compound, the reactor resumed 2-FP degradation. The inoculated strain was retained within the biofilm in the disks, as the 2-FP degrading strain was recovered

from the biofilm by the end of the experiment, thus bioaugmentation was successfully achieved.
\end{abstract}

Rotating biological contactor (RBC)

2-Fluorophenol (2-FP)

Bioaugmentation

\section{Introduction}

The biodegradation of fluorinated compounds, such as 2-fluorophenol (2-FP), has been scarcely reported. These compounds are widely used as aerosol propellants, surfactants, agrochemicals, adhesives, refrigerants, fire retardants, pharmaceuticals, among others. These pollutants may occur in wastewaters discontinuously and at low concentrations, leading to the need of developing efficient bioreactors capable to deal with this scenario. Rotating biological contactors (RBCs) are bioreactor systems with high biomass retention that are extremely promising for such situations. These systems constitute a very attractive technology for low cost wastewater treatment due to operational features such as short hydraulic retention times, excellent capacity to deal with shock and toxic loadings, simple design and operation, high treatment efficiency and low energy requirement (Chowdhury et al., 2010; Cortez et al., 2008; Sirianuntapiboon, 2006). RBCs have been successfully used to treat several organopollutants, such as chlorophenols, phenol and trichloroethylene (Alemzadeh et al., 2002; Brar and Gupta, 2000; Majumber and Gupta, 2007; Sahinkaya and Dilek, 2006).

The main aim of this study was to investigate the performance of a laboratory scale RBC towards organic shock loadings with 2-FP before and after bioaugmentation with a specialized strain able to degrade this compound.

* Corresponding author. Tel.: +351 225580059; fax: +351 225090351.

E-mail addresses: afduque@mail.esb.ucp.pt (A.F. Duque), vsbessa@esb.ucp.pt (V.S. Bessa), mfcarvalho@esb.ucp.pt (M.F. Carvalho), plcastro@esb.ucp.pt (P.M.L. Castro).

\section{Methods}

\section{1. $R B C$ set up and operation}

Two $10 \mathrm{~L} \mathrm{RBC}$ units containing each five stages $(5 \mathrm{~cm}$ distance; baffles on the bottom) with 10 PVC discs ( $3 \mathrm{~mm}$ thick; diameter $16.5 \mathrm{~cm}$; spaced $1 \mathrm{~cm}$ apart; $40 \%$ of disc submergence) were operated in series (Fig. 1). The reactor was inoculated with $5 \mathrm{~L}$ of activated sludge from the return sludge flow of a conventional wastewater treatment plant and $5 \mathrm{~L}$ of synthetic wastewater containing sodium acetate for biofilm formation. During the first 18 days, the RBC was fed every day, in a batch mode, with $200 \mathrm{mg} \mathrm{L}^{-1}$ acetate and from day 19 the reactor was operated in a continuous mode (Table 1$)$. The hydraulic loading rate (HLR) applied was $0.25 \mathrm{dm}^{3} \mathrm{~m}^{-2} \mathrm{~h}^{-1}$ and the rotational speed of the discs was $12 \mathrm{rpm}$.

\subsection{Bioaugmentation with the 2-FP degrading strain}

Bioaugmentation of the RBC with a bacterial strain able to degrade 2-FP, named as strain FP1, isolated in our laboratories (unpublished), was performed. FP1 pure cultures were grown in sealed flasks containing a mineral salts liquid medium (Carvalho et al., 2006) and 2-FP at a concentration of $50 \mathrm{mg} \mathrm{L}^{-1}$. The cultures were incubated on an orbital shaker $(100 \mathrm{rpm})$ at $25^{\circ} \mathrm{C}$. The reactor was inoculated with $2 \mathrm{~L}$ of an FP1 pure culture with an optical density at $600 \mathrm{~nm}\left(\mathrm{OD}_{600}\right)$ of 0.4 and fed with $50 \mathrm{mg} \mathrm{L}^{-1}$ of 2-FP, after which it was left for about 2 weeks as a closed system. The feeding regime presented in Table 1 was followed thereafter. 


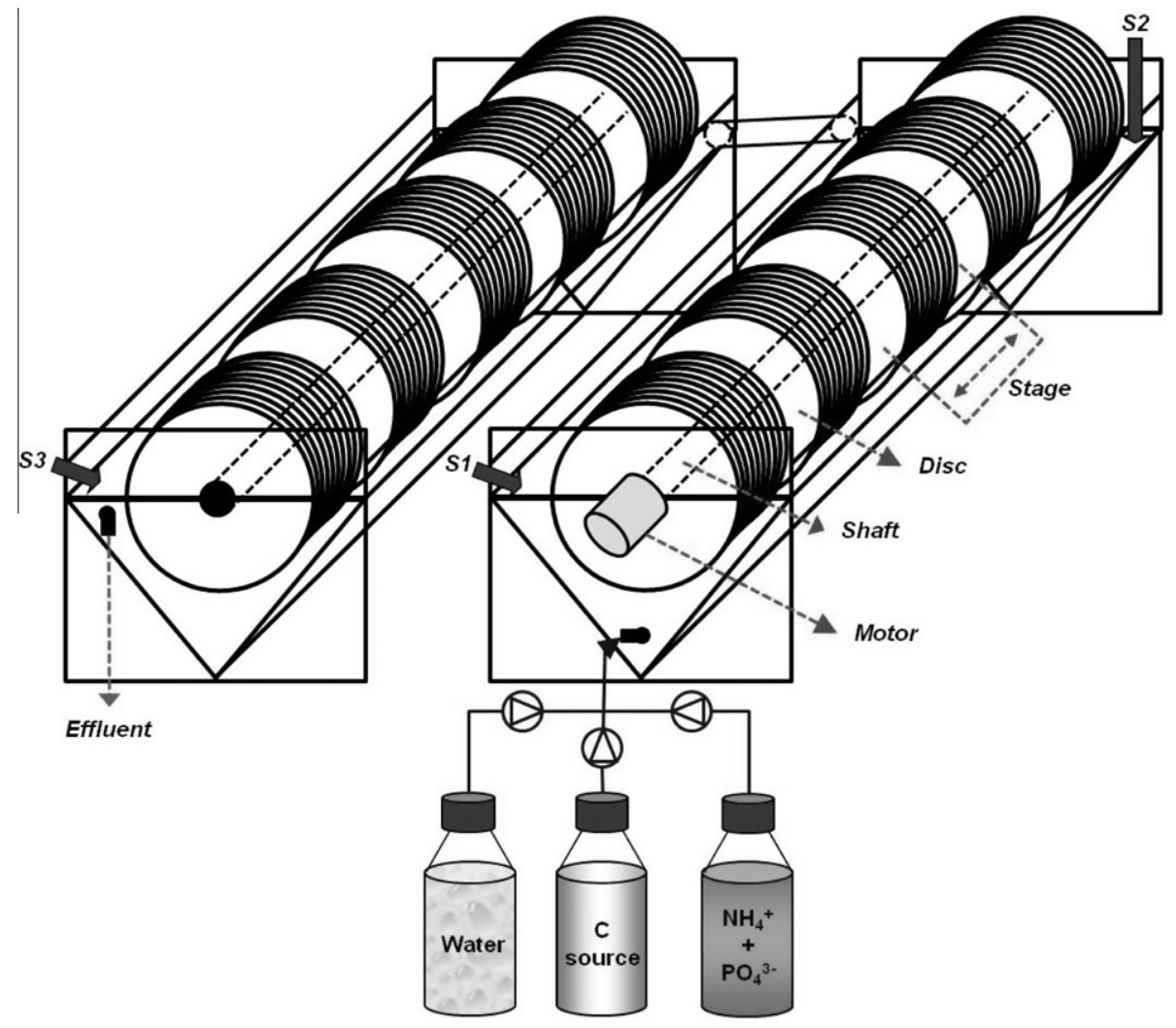

Fig. 1. Schematic representation of the RBC. S1, S2 and S3 are sampling points located in the 1st, 5th and 10th stages, respectively.

\subsection{Synthetic wastewater composition}

The composition of the influent medium was as described by Beun et al. (2002), but with a sodium acetate inlet concentration of $200 \mathrm{mg} \mathrm{L}^{-1}$. During 2-FP shock loadings, 2-FP was added to the medium in order to reach the range of 2-FP inlet concentrations described in Table 1.

\subsection{Analysis}

Dissolved oxygen (DO) and $\mathrm{pH}$ in the reactor were measured with a WTW 91 handheld multi-parameter instrument 340i. Chemical oxygen demand (COD) was determined according to Standard Method 5220 (APHA, 1998). The fluoride concentration was measured with a fluoride electrode (Carvalho et al., 2006) and 2-FP in filtered samples was analyzed by high performance liquid chromatography (HPLC; Beckman System Gold 126, Fullerton, USA) with a LiChroCART $^{\circledR}$ 25-4 LiChrospher $^{\circledR} 100$ RP-18 reversed-phase column ( $5 \mu \mathrm{m}$ particle size; Merck, Darmstadt, Germany). The mobile phase consisted of $50 \%(\mathrm{v} / \mathrm{v})$ acetonitrile/ water and was used at a flow rate of $0.8 \mathrm{ml} \mathrm{min}{ }^{-1}$ (run time $10 \mathrm{~min}$; injected volume - $20 \mu \mathrm{l}$ ). The compound was detected at $220 \mathrm{~nm}$ using a diode array detector.

\subsection{Recovering of strain FP1 from the $R B C$}

\subsubsection{Bacterial isolation and DNA extraction}

Biofilm samples from the 1 st disc of the 1st stage of the RBC were scrapped with a scalpel. The biofilm was then subjected to sonication for a total time of $1 \mathrm{~min}$ ( 2 cycles of $30 \mathrm{~s}$ at $97 \%$ of $20 \mathrm{kHz}$ ) (SONOPLUS ultrasonic homogenizer HD 2070; BANDELIN electronic, Berlin, Germany). Resulting supernatant was plated as described by Emanuelsson et al. (2008). Bacteria isolation and DNA extraction was performed according to Calheiros et al. (2010).

\subsubsection{DNA sequencing analysis}

Isolates were identified by $16 \mathrm{~S}$ rRNA sequencing analysis. Amplification was carried out with the universal primers $f 27$ and r1492 (Lane, 1991), as previously described (Emanuelsson et al., 2008). The amplified fragments were sequenced by Macrogen Inc. (Seoul, Republic of Korea). To determine the phylogenetic affiliation, similarity analyses were performed using the BLAST program (Altschul et al., 1997).

\section{Results and discussion}

The RBC treatment efficiency was followed through the evaluation of the parameters biological removal efficiency (BRE) and biological elimination capacity (BEC), which were calculated by considering only the fraction of 2-FP biologically degraded.

Throughout reactor operation, $\mathrm{DO}$ concentration and $\mathrm{pH}$ at the different stages of the RBC were in the range of 3.7-10 $\mathrm{mg} \mathrm{O}_{2} \mathrm{~L}^{-1}$ and 6.6-7.5, respectively. This indicates that none of these parameters were limiting factors for the reactor operation.

\section{1. $R B C$ performance - 2-FP degradation by unacclimated sludge}

The reactor was operated for 1 year and 5 months with a hydraulic retention time (HRT) of $18.6 \mathrm{~h}$. The overall operational performance of the RBC is shown in Fig. 2. During phase I (16 days), acetate was continuously fed to the reactor with the objective of achieving a stable and thick biofilm. From phase II to phase IX (days 36-126) the reactor was subjected, every 2 weeks, to organic shock loadings of $25 \mathrm{mg} \mathrm{L}^{-1}$ 2-FP during $48 \mathrm{~h}$, mimicking scenarios of industrial wastewaters where these micropollutants may occur discontinuously. As it can be observed in Fig. 2, there was no indication of 2-FP biodegradation during the 90 days period of intermittent organic shocks, with no fluoride released. However, 2-FP was not detected in the outlet, indicating that the compound 
Table 1

Degradation of 2-FP in the RBC under several operating conditions.

\begin{tabular}{|c|c|c|c|c|c|c|}
\hline \multirow[t]{2}{*}{ Phase } & \multirow[t]{2}{*}{ Length of operation (days) } & \multirow[t]{2}{*}{ Days of operation } & \multicolumn{2}{|c|}{ Inlet carbon sources concentrations $\left(\mathrm{mg} \mathrm{L}^{-1}\right)$} & \multirow[t]{2}{*}{$\operatorname{BRE}^{\mathrm{a}, \mathrm{c}}(\%)$} & \multirow[t]{2}{*}{$\mathrm{BEC}^{\mathrm{b}, \mathrm{c}}\left(\mathrm{g}_{2-\mathrm{FP}} \mathrm{d}^{-1} \mathrm{~m}^{-2}\right)$} \\
\hline & & & $\mathrm{NaAc}$ & 2-FP & & \\
\hline & $0-18$ & 18 & 200 & 0 & NA & NA \\
\hline I & $19-35$ & 16 & 200 & 0 & - & - \\
\hline II & $36-38$ & 2 & 200 & 25 & - & - \\
\hline III & $39-69$ & 30 & 200 & 0 & - & - \\
\hline IV & $70-72$ & 2 & 200 & 25 & - & - \\
\hline $\mathrm{V}$ & $73-83$ & 10 & 200 & 0 & - & - \\
\hline VI & $84-86$ & 2 & 200 & 25 & - & - \\
\hline VII & $87-97$ & 10 & 200 & 0 & - & - \\
\hline VIII & $98-100$ & 2 & 200 & 25 & - & - \\
\hline IX & $101-126$ & 25 & 200 & 0 & - & - \\
\hline $\mathrm{X}$ & $127-144$ & 17 & \multicolumn{4}{|c|}{ Bioaugmentation with strain $F P 1^{\mathrm{d}}$} \\
\hline $\mathrm{XI}$ & $145-152$ & 7 & 200 & 0 & - & - \\
\hline XII & $153-155$ & 2 & 200 & 25 & $22 \pm 7$ & $0.33 \pm 0.1$ \\
\hline XIII & $156-166$ & 10 & 200 & 0 & - & - \\
\hline XIV & $167-169$ & 2 & 200 & 25 & $20 \pm 6$ & $0.30 \pm 0.1$ \\
\hline$X V$ & $169-177$ & 8 & 200 & 0 & - & - \\
\hline XVI & $178-185$ & 7 & 200 & 25 & $50 \pm 6$ & $0.73 \pm 0.1$ \\
\hline XVII & $186-240$ & 54 & 200 & 50 & $81 \pm 6$ & $2.4 \pm 0.2$ \\
\hline XVIII & $241-243$ & 2 & 200 & 100 & $82 \pm 27$ & $4.8 \pm 1.6$ \\
\hline XIX & $244-254$ & 10 & 200 & 50 & $110 \pm 6$ & $3.2 \pm 0.2$ \\
\hline $\mathrm{XX}$ & $255-257$ & 2 & 200 & 100 & $64 \pm 14$ & $3.8 \pm 0.8$ \\
\hline XXI & $258-261$ & 3 & 200 & 50 & $126 \pm 6$ & $3.7 \pm 0.3$ \\
\hline XXII & $262-264$ & 2 & 200 & 100 & $50 \pm 1$ & $2.9 \pm 0.1$ \\
\hline XXIII & $265-290$ & 25 & 200 & 50 & $112 \pm 8$ & $3.3 \pm 0.2$ \\
\hline XXIV & $291-293$ & 2 & 200 & 100 & $22 \pm 2$ & $1.3 \pm 0.1$ \\
\hline $\mathrm{XXV}$ & 294-304 & 10 & 200 & 50 & $69 \pm 3$ & $2.0 \pm 0.1$ \\
\hline XXVI & $305-307$ & 2 & 200 & 200 & $16 \pm 1$ & $1.9 \pm 0.2$ \\
\hline XXVII & $308-317$ & 9 & 200 & 50 & $86 \pm 9$ & $2.6 \pm 0.2$ \\
\hline XXVIII & $318-346$ & 28 & \multicolumn{4}{|c|}{ Starvation period } \\
\hline XXIX & $347-360$ & 13 & 200 & 0 & - & - \\
\hline $\mathrm{XXX}$ & $361-496$ & 135 & 200 & 50 & $76 \pm 5$ & $2.2 \pm 0.1$ \\
\hline
\end{tabular}

a BRE - biological removal efficiency.

b BEC - biological elimination capacity.

c The values listed are means \pm standard error of the mean (SEM).

d Strain FP1 - 2-FP degrading strain; NA - not applicable.

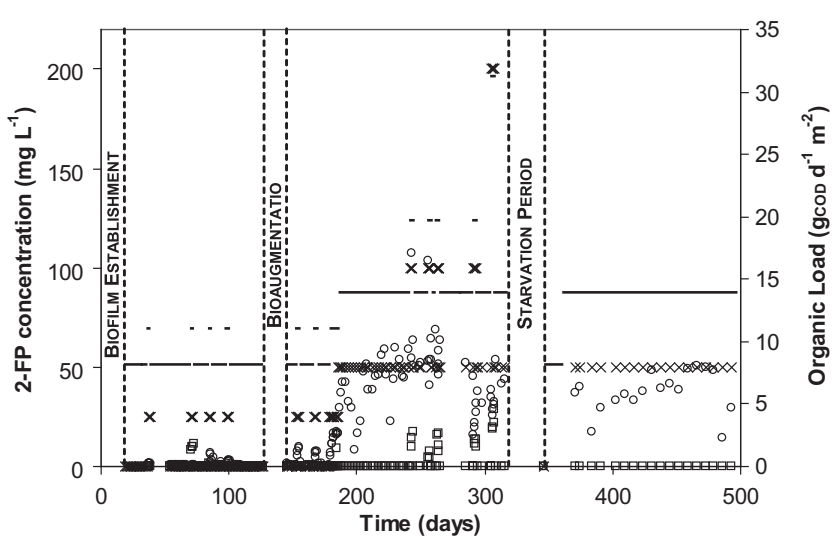

Fig. 2. Biodegradation of 2-FP in the RBC. 2-FP inlet concentration $(x)$, 2-FP outlet concentration ( $\square$ ), 2-FP degraded based on fluoride release $(O)$ and organic load based on acetate and 2-FP COD (-) are indicated.

was probably adsorbed to the biofilm matrix. Most of the studies reported in the literature started the acclimatization period with the target pollutant, such as phenol, chlorophenols and trichloroethylene in the feeding and reached complete degradation for the range tested (between 20 and $125 \mathrm{mg} \mathrm{L}^{-1}$ ) (Brar and Gupta, 2000; Chavan and Mukherji, 2010; Majumber and Gupta, 2007). In this study, the $48 \mathrm{~h}$ shocks could have been insufficient for microbial acclimatization, however, even if the time period of the shocks had been longer, acclimatization to 2-FP would have been unlikely to occur due to the highly recalcitrance exhibited by fluorinated

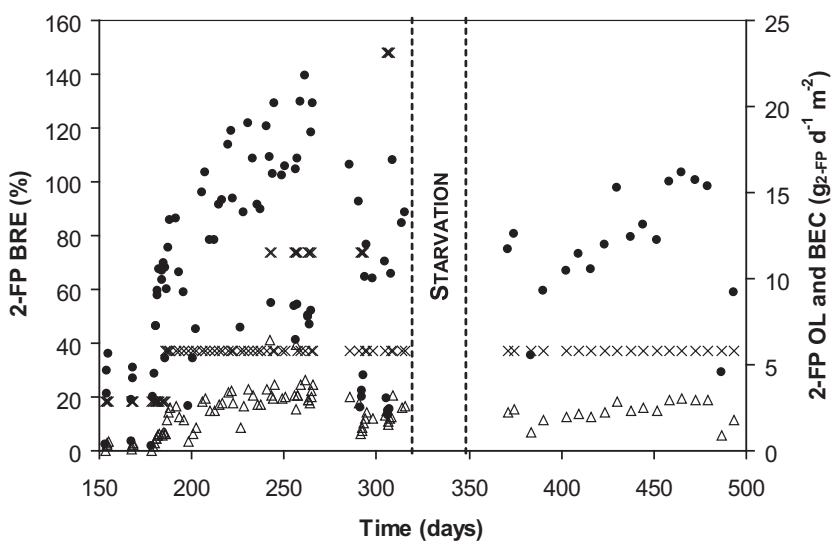

Fig. 3. Performance of the RBC after bioaugmentation with strain FP1. 2-FP Organic load $(\times)$, 2-FP BRE $(\bullet)$ and 2-FP BEC $(\triangle)$ are indicated.

organics. Gentry et al. (2004) reported that bioaugmentation has been shown to improve degradation of various toxic compounds, such as chlorinated compounds and phenols. Therefore, the RBC was, subsequently, bioaugmented with a bacterial strain able to degrade 2-FP, strain FP1.

\section{2. $R B C$ performance after augmentation with the 2-FP degrading strain}

The bioaugmentation of the RBC, phase $X$ (days 127-144), was performed in batch mode, in order to avoid loss of strain FP1 and 
to promote the attachment of the bacterial strain to the biofilm. During phases XI-XVI, the operational strategy used in the RBC was similar to that used before bioaugmentation and from phase XVII, the RBC was continuously fed with 2-FP $\left(25-200 \mathrm{mg} \mathrm{L}^{-1}\right)$ (Table 1). The performance obtained in each phase throughout the operation of the RBC after bioaugmentation is summarized in Table 1. A step increase in fluoride release was observed and 2FP complete biodegradation was reached by day 206 (phase XVII), indicating that bioaugmentation was successfully achieved (Fig. 2). Accordingly, a step increase in the BRE and BEC was also observed, reaching in phase XVII a value of ca. $81 \%$ and ca. $2.4 \mathrm{~g} \mathrm{~d}^{-1} \mathrm{~m}^{-2}$, respectively (Table 1 and Fig. 3). With the exception of phase XVIII, where the RBC showed the highest BEC value (ca. $4.8 \mathrm{~g} \mathrm{~d}^{-1} \mathrm{~m}^{-2}$ ), a decrease in the BRE and BEC was observed in phases XX, XXII and $X X I V$, indicating that the RBC was not able to deal with the applied concentrations, probably due to an acute toxic effect of 2-FP at higher concentrations. Operational conditions, like HRT and HLR, could be optimized in order to achieve higher degradation rates when treating higher 2-FP concentrations $\left(>50 \mathrm{mg} \mathrm{L}^{-1}\right)$; it is possible that a more gradual increase of the concentration of 2-FP could have led to the acclimatization of the biomass to higher concentrations, however in the present work the main objective was to investigate the behavior of the RBC towards 2-FP shock loadings, mimicking an effluent where this kind of micropollutants may occur discontinuously. BRE values higher than $100 \%$ were obtained in phases XIX, XXI and XXIII, indicating that the biofilm was highly active, biodegrading both the 2-FP fed in the influent and the 2FP previously adsorbed onto the biofilm matrix.

Periods of substrate absence can affect biofilm survival and, mainly, maintenance of microbial activity. In phase XXVIII, a starvation period of $28 \mathrm{~d}$ was applied to the RBC, in order to mimic a period of plant shutdown. The feed was then re-established at day 347 (phase XXIX) with acetate as sole carbon and energy sources and from phase XXX, the RBC was fed again with $50 \mathrm{mg} \mathrm{L}^{-1}$ of 2-FP. During phase XXX, the obtained BRE and BEC values were similar to those achieved in phase XXVII, before the starvation period, indicating that the degrading biofilm remained active after the period of substrate absence (Fig. 3). Immobilized reactors have demonstrated capacity to preserve biofilm survival and activity after starvation periods (Carvalho et al., 2006; Emanuelsson et al., 2008; Sahinkaya and Dilek, 2006).

The 2-FP degradation occurring at the different stages of the $\mathrm{RBC}$ was investigated (data not shown). It was observed that the 1st stage of the RBC had the higher contribution to the removal of 2-FP, suggesting that strain FP1 was mainly present in the 1st stage. Therefore, only the area of the 1 st stage was taken into account for the BEC calculation.

\subsection{Recovering of strain FP1 from the RBC}

In order to assess the success of the bioaugmentation biofilm samples were collected and plated in NA and recovered isolates were characterized through 16S rRNA gene analysis. According to Blast results strain FP1 was recovered from the reactor, which strongly indicates the success of the bioaugmentation. Successfully incorporation of bioaugmented strains within granular activated carbon biofilm reactors has been reported (Carvalho et al., 2006; Emanuelsson et al., 2008).

\section{Conclusions}

This study demonstrated the applicability of RBCs in the biological treatment of wastewaters containing toxic compounds, like 2-FP.

- After bioaugmentation with strain FP1, the RBC showed good removal performances for 2-FP concentrations up to $50 \mathrm{mg} \mathrm{L}^{-1}$, reinforcing that bioaugmentation is often necessary when biodegradation of highly recalcitrant compounds is targeted;

- The RBC was able to deal with a substrate absence period, mimicking a plant shutdown season, being capable to recover its performance;

- After ca. 350 days of operation, strain FP1 was successfully recovered from the RBC biofilm.

\section{Acknowledgements}

A.F. Duque and M.F. Carvalho wish to acknowledge a Research Grant from Fundação para a Ciência e Tecnologia (FCT), Portugal (Ref. SFRH/BD/30771/2006 and SFRH/BPD/44670/2008, respectively) and Fundo Social Europeu (III Quadro Comunitário de Apoio). This work was supported by Project PTDC/BIO/67306/2006.

\section{References}

Alemzadeh, I., Vossoughi, M., Houshmandi, M., 2002. Phenol biodegradation by rotating biological contactor. Biochem. Eng. J. 11, 19-23.

Altschul, S.F., Madden, T.L., Schaffer, A.A., Zhang, J., Zhang, Z., Miller, W., Lipman, D.J., 1997. Gapped BLAST and PSI-BLAST: a new generation of protein database search programs. Nucleic Acids Res. 25, 3389-3402.

APHA, 1998. Standard Methods: For the Examination of Water and Wastewater, 20th ed. American Public Health Association/American Water Works Association/Water Environment Federation, Whashigton, DC, USA.

Beun, J.J., van Loosdrecht, M.C.M., Heijnen, J.J., 2002. Aerobic granulation in a sequencing batch airlift reactor. Water Res. 36, 702-712.

Brar, S.K., Gupta, S.K., 2000. Biodegradation of trichloroethylene in a rotating biological contactor. Water Res. 34, 4207-4214

Calheiros, C.S.C., Teixeira, A., Pires, C., Franco, A.R., Duque, A.F., Crispim, L.F.C., Moura, S.C., Castro, P.M.L., 2010. Bacterial community dynamics in horizontal flow constructed wetlands with different plants for high salinity industrial wastewater polishing. Water Res. 44, 5032-5038.

Carvalho, M.F., Ferreira Jorge, R., Pacheco, C.C., De Marco, P., Henriques, I.S., Correia, A., Castro, P.M.L., 2006. Long-term performance and microbial dynamics of an up-flow fixed bed reactor established for the biodegradation of fluorobenzene. Appl. Microbiol. Biotechnol. 71, 555-562.

Chavan, A., Mukherji, S., 2010. Effect of co-contaminant phenol on performance of a laboratory-scale RBC with algal-bacterial biofilm treating petroleum hydrocarbon-rich wastewater. J. Chem. Technol. Biotechnol. 85, 851-859.

Chowdhury, P., Viraraghavan, T., Srinivasan, A., 2010. Biological treatment processes for fish processing wastewater - a review. Bioresour. Technol. 100, 5010-5015.

Cortez, S., Teixeira, P., Oliveira, R., Mota, M., 2008. Rotating biological contactors: review on main factors affecting performance. Rev. Environ. Sci. Biotechnol. 7, 155-172.

Emanuelsson, M.A.E., Osuna, M.B., Sipma, J., Castro, P.M.L., 2008. Treatment of halogenated organic compounds and monitoring of microbial dynamics in upflow fixed bed reactors under sequentially alternating pollutant scenarios. Biotechnol. Bioeng. 99, 800-810.

Gentry, T.J., Rensing, C., Pepper, I.L., 2004. New approaches for bioaugmentation as a remediation technology. Crit. Rev. Environ. Sci. Technol. 34, 447-494.

Lane, D.J., 1991. 16S/23S rRNA sequencing. In: Stackebrandt, E., Goodfellow, M. (Eds.), Nucleic Acid Techniques in Bacterial Systematics. John Wiley and Sons Ltd., West Sussex, England.

Majumber, P.S., Gupta, S.K., 2007. Removal of chlorophenols in sequential anaerobic-aerobic reactors. Bioresour. Technol. 98, 118-129.

Sahinkaya, E., Dilek, F.B., 2006. Biodegradation of 4-CP and 2,4-DCP mixture in a rotating biological contactor (RBC). Biochem. Eng. J. 31, 141-147.

Sirianuntapiboon, S., 2006. Treatment of wastewater containing $\mathrm{Cl}_{2}$ residue by packed cage rotating biological contactor (RBC) system. Bioresour. Technol. 97, 1735-1744. 